\title{
Urszula Chęcińska*
}

\section{0 pedagogice epistolarnej jako sztuce życia Listy prof. Zygmunta Mysłakowskiego do Joanny Kulmowej (1963-1971) Epistolary Pedagogy as the Art of Life Letters from Professor Zygmunt Mysłakowski to Joanna Kulmowa (1963-1971)}

\begin{abstract}
Professor Zygmunt Mysłakowski (1890-1971), a distinguished cultural educator, education theorist, philosopher and artist. 'I am convinced that there is a link between scientific and artistic creation, which comes to the fore in the scientific synthesis of phenomena', wrote Mysłakowski. This thought is confirmed by the correspondence of Professor Mysłakowski with the poet and writer Joanna Kulmowa (1928-2018). It is a special kind of cultural pedagogy. It could be called epistolary pedagogy, defined as a kind of psychological and pedagogical reflection on the world of culture. Epistolary pedagogy, conducive to creative expression, becomes an autotelic and aesthetic quality in Mysłakowski's work. This is related to the permanent system of cultural references and cultural contexts inscribed in the contemporary autobiographical scientific discourse through letters perceived as personal documents. The article announces the publication of letters from Professor Mysłakowski to Kulmowa.

Keywords: epistolary pedagogy, pedagogy of culture, biography, letter.

* Urszula Chęcińska (ORCID: 00oo-0oo2-0416-1691) dr hab., prof. Uniwersytetu Szczecińskiego, kierownik Katedry Wczesnej Edukacji w Instytucie Pedagogiki us oraz Pracowni Badań nad Twórczością Joanny Kulmowej, twórczyni serii Biblioteka Katedry Wczesnej Edukacji; kontakt: urszula.checinska@ usz.edu.pl.
\end{abstract}




\section{Wstęp}

7 ygmunt Mysłakowski, kierownik pierwszej Katedry Pedagogiki w Polsce, założonej na Uniwersytecie Jagiellońskim, zmarł w Krakowie 1 paździer-

1 Materiały z sesji, wzbogacone fragmentami dysertacji doktorskich Lidii Jastrzębskiej-Majer i Kazimierza Szmyda, wspomnieniami syna Piotra Mysłakowskiego, a także wypowiedziami profesorów: Feliksa Grossa, Stefana Wołoszyna, Czesława Banacha i Włodzimierza Szewczuka, dodatkowo dopełnione nową bibliografią prac Mysłakowskiego i Kalendarium życia Zygmunta Mysłakowskiego w opracowaniu P. Mysłakowskiego, ukazały się w 1999 r. nakładem Instytutu Badań Edukacyjnych i Studia Wydawniczego „Familia”; W poszukiwaniu podstaw pedagogiki. Zygmunt Mysłakowski (1890-1971), red. T. W. Nowacki, Warszawa 1999.

2 L. Chmaj, Pedagogika kultury, w: tegoż, Prądy i kierunki w pedagogice XX wieku, Warszawa 1963, s. 414- 418.

3 S. Baścik Życiorys naukowy Prof. Dr. Zygmunta Mysłakowskiego, w: Z. Mysłakowski. Pisma wybrane, red. T. Nowacki, Warszawa 1971, s. 9-35.

4 T. Nowacki, Recepcja myśli pedagogicznej Zygmunta Mysłakowskiego, w: W poszukiwaniu podstaw pedagogiki, s. 196-213.

5 W. Okoń, Zygmunt Mysłakowski-pedagog dwóch epok, w: tegoż, Wizerunki sławnych pedagogów polskich, Warszawa 2000, s. 309-333.

6 G. Michalski, Zygmunt Mysłakowski (1890-1971). Działalność i twórczość pedagogiczna, Łódź 1994.

7 K. Szmyd, Zygmunt Karol Mysłakowski (1890-1971). Twórczośc i wkład do rozwoju nauk o wychowaniu, Rzeszów 1997.

8 J.Torowska, Selected Aspects of Zygmunt Mysłakowski's Work Entitled O kulturze wspótżycia. Rozważania i propozycje [On the Culture of Coexistence: Considerations and Propositions] in the Light of His Biography, „Biografistyka Pedagogiczna”, 5 (2020) nr 2, s. 125-149, DOI: 10.36578/BP.2020.05.07.

9 P. Mysłakowski, Mysłakowscy z Ziemi Dobrzyńskiej. W górę rzeki. Wspomnienia, teksty i materiały, Warszawa 1997. nika 1971 r., pięćdziesiąt lat temu. Pedagogiczna myśl Zygimunta Mysłakowskiego stała się przedmiotem konferencji naukowej zorganizowanej przez Oddział Łomżyński Wyższej Szkoły Pedagogicznej w Olsztynie ${ }^{1}$ w 1990 r. z okazji setnej rocznicy urodzin profesora. W Komitecie Honorowym utworzonym pod patronatem Ministerstwa Edukacji Narodowej i ministra Henryka Samsonowicza, jako przewodniczącego, zasiadali wybitni polscy profesorowie: Andrzej Ajnenkiel, Aleksander Geysztor, Stanisław Kawula, Tadeusz Nowacki, Stefan Wołoszyn i Ryszard Bender.

Pedagogiczna twórczość prof. Mysłakowskiego znalazła swoje omówienie w wielu publikacjach, m.in.: Ludwika Chmaja ${ }^{2}$, Stefana Baścika ${ }^{3}$, Tadeusza Nowackiego ${ }^{4}$, Wincentego Okonia ${ }^{5}$, Grzegorza $\mathrm{Mi}-$ chalskiego $^{6}$, Kazimierza Szmyda ${ }^{7}$, a ostatnio Joanny Torowskiej ${ }^{8}$. Niekonwencjonalną wartość naukową zyskała także publikacja pt. Mysłakowscy z Ziemi Dobrzyńskiej. W górę rzeki. Wspomnienia, teksty i materiaty opracowana przez Piotra Mysłakowskiego 9 . Monografia, opatrzona licznymi rodzinnymi fotografiami 
i tablicami genealogicznymi rodu Mysłakowskich, zawiera niepublikowane fragmenty wspomnień Zygmunta Mysłakowskiego i jego żony Łucji Mysłakowskiej. W archiwum synów profesora: Piotra Mysłakowskiego i Pawła Mysłakowskiego zachowała się także interesująca korespondencja znakomitego pedagoga z Joanną Kulmową, poetką i pisarką, której twórczość stała się przedmiotem wielu rozpraw naukowych ${ }^{10}$. Życzeniem zmarłego w $2019 \mathrm{r}$. męża poetki, Jana Kulmy, było jej opublikowanie i udostępnienie szerszemu kręgowi czytelników.

Niniejszy artykuł jest zapowiedzią publikacji korespondencji Zygmunta Mysłakowskiego z Joanną Kulmową, która w przekonaniu Jana Kulmy stanie się dla współczesnych czytelników ważną lekturą o głębokim, humanistycznym przesłaniu. Korespondencja, doświadczonego pedagoga $\mathrm{z}$ młodą poetką, obejmuje 88 listów wysyłanych z Krakowa, Zawoi i Strumian w latach 1963-1971. Wartość tej korespondencji, ze względu na jej pedagogiczne walory i wysoką artystyczną sztukę słowa, jest niekwestionowana. Mysłakowski, autor takich pojęć jak "plan życiowy”, tez o „podwójnej funkcji wychowania" i roli talentu pedagogicznego przywiązywał ogromną wagę do wartości słowa. Tego żywego, którego był niekwestionowanym mistrzem ${ }^{11}$, i tego pisanego, o które wzorem Cypriana Kamila Norwida dbał w sposób szczególny. „Słowo ma wartości wewnętrzne o ogromnym znaczeniu dla człowieczeństwa"12, podkreślał w tomie pt. $O$ kulturze wspótżycia. Kto niszczy funkcję słowa - ostrzegał - ten niszczy własne człowieczeństwo.

10 Dziecko i jego światy w poezji dla dzieci, red. U. Chęcińska, Szczecin 1993, s. 17-77; Joanna Kulmowa wobec świata literatury, red. tejże, Szczecin 1998; tejże, Poetka i paidia. O muzie dziecięcej Joanny Kulmowej, Szczecin 2006; Joanna Kulmowa. Doctor Honoris Causa Uniwersytetu Szczecińskiego, red. tejże, Szczecin 2012; Bibliografia i ikonobibliografia twórczości Joanny Kulmowej, oprac. i wstęp tejże, Szczecin 2012; tejże, Edukacja małego dziecka. Joanny Kulmowej pajdologia poetycka in extenso, $\mathrm{w}$ : Children in the Postmodern World. Culture Media - Social Inequality, red. H. Krauze-Sikorska, M. Klichowski, A. Basińska, Poznań 2014, s. 269-281; A. Książek-Szczepanikowa, Zawiązki Joanny Kulmowej wielokrotnie odczytane. Tekst - rozumienie aplikacja, Szczecin 2001; tejże, „Na ten słodki czas”. Spotkania z Joanną Kulmową i jej poezją w latach 1982-1996, Siedlce 2004; tejże, Joanna ze Strumian. Tylko szkic... Szczecin 2015; tejże, Joanny Kulmowej „poezja otwarta”, Łódź 2017; G. Leszczyński, Joanna Kulmowa: „bajka o nadziei, odwadze i mądrości”, Warszawa 2018.

11 Cz. Banach, Wspomnienie i rozmowa o profesorze Zygmuncie Mysłakowskim, w: W poszukiwaniu podstaw pedagogiki, s. 267-279.

12 Z. Mysłakowski, Obcowanie pośrednie - za pomoca słowa, w: tegoż, O kulturze wspótżycia. Rozważania i propozycje, Warszawa 1969, s. 69. 


\section{List jako forma pedagogicznego uobecnienia}

O tym, że list jest „cząstką życia”, posiada bezpośredni z nim związek, sytuując się na pograniczu literatury i kultury, „z dala od «gwaru» bezpośredniej rzeczywistości"13 - pisała Stefania Skwarczyńska.

Współrzędność listu wobec życia lub jego z nim bezpośredni związek jako cząstki z całością - jest istotą charakteru listu. Nie ma prawdziwego listu pozbawionego tego podstawowego związku z życiem. A zatem nie ma piękna w liście, który by nie miał należycie jasno wyrysowanej linii swego stosunku do życia ${ }^{14}$

pisała Skwarczyńska w monumentalnej monografii pt. Teoria listu, wydanej w 1937 r. nakładem Towarzystwa Naukowego we Lwowie. W jej oryginalnej koncepcji piękno listu powinno wynikać z postawy życiowej adresata jako współtwórcy listu, z jego potrzeby kontaktu z drugim człowiekiem. I taka jest korespondencja prof. Mysłakowskiego z poetką i pisarką, Joanną Kulmową, autorką radiowych Listów ze Strumian, emitowanych w Polskim Radiu Szczecin w latach osiemdziesiątych. List potraktowany jako autonomiczny tekst kultury jest w każdym przypadku egzemplifikacją wzajemnych relacji między nadawcą a odbiorcą, ma ewidentny wpływ na uprawianą przez nich sztukę życia.

List staje się zatem zapisem kulturalnej rozmowy, przeżywanej zarówno przez nadawcę, jak i odbiorcę jako rodzaj wysokoartystycznego samostanowienia, autokreacji i sprawczości. Kazimierz Cysewski jako pierwszy połączył pojęcie autokreacji z listem ${ }^{15}$, rozpatrując autokreację jako pojęcie literaturoznawcze. O wymiarze biograficznym, kulturowym, aksjologicznym i agato-

13 S. Skwarczyńska, Teoria listu, na podstawie lwowskiego pierwodruku opracowali E. Feliksiak i M. Leś, Białystok 2006, s. 29-30.

14 Tamże, s. 333.

15 K. Cysewski, Problem autokreacji w listach Zygmunta Krasińskiego, w: Sztuka pisania. O liście polskim $w$ wieku XIX, red, J. Sztachelska, E. Dąbrowicz, Białystok 2000, s. 73-97.

16 A. Całek Od autokreacji do kreowania wizerunku w liście, w: tejże, Nowa teoria listu, Kraków 2019, S. 141-172. logicznym autokreacji pisze Anita Całek w Nowej teorii listu ${ }^{16}$. Jej zdaniem list jest swoistym połączeniem sztuki i życia. W interakcję z autokreacją wchodzi, zdaniem Całek, autoprezentacja, która wiąże się z wizerunkiem nadawcy i odbiorcy listu. Odnosząc się do własnego wizerunku zarówno w wymiarze biograficznym, aksjologicznym, jak i stylistycznym 
nadawca i odbiorca w ewidentny sposób wpływają więc na kształt listu, na kreowanie własnej „tożsamości pożądanej”, którą Anita Całek za Elżbietą Rybicką określa „tożsamością komunikacyjną"17.

Prof. Mysłakowski, jako pedagog, ukierunkowuje własną pedagogiczną autokreację tak, aby stanowiła ona punkt odniesienia dla kreatywnego rozwoju młodej poetki. Zapisując w listach do Kulmowej kulturalne formy istnienia człowieka, wskazuje wagę dziedzictwa kulturowego, rolę więzi międzyludzkich, podlegającej regułom komunikacyjnym, wiedzy emocjonalnej, mającej istotny wpływ na rozwój tożsamości człowieka. Pedagogika, którą uprawia w listach do Kulmowej, stanowi szczególny rodzaj pedagogiki kultury, której podstawą jest humanistyczny sposób pojmowania człowieka i świata ${ }^{18}$. Nazwać by ją można pedagogiką epistolarną definiowaną jako rodzaj pedagogiczno-psychologicznej refleksji nad światem kultury ${ }^{19}$. Wiąże się ona z trwałym systemem kulturalnych odniesień i kulturowych kontekstów wpisujących się we współczesny autobiograficzny dyskurs naukowy poprzez list jako dokument osobisty i źródło wiedzy o życiu indywidualnym i zbiorowym. Mysłakowski posiada pełną świadomość, że list to niekonwencjonalna forma pedagogicznego uobecnienia, autokreacji i autoreprezentacji. Jak sam napisze w tomie pt. O kulturze wspótżycia, list to „ustabilizowana pośrednia forma styczności osobistej, która stanowić może warunek wspólnoty przeżyć i oddziaływania wychowawczego" ${ }^{\prime 2}$. List jako gatunek proteuszowy ${ }^{21}$, rozpatrywany na obszarze pedagogiki, zyskuje niekonwencjonalną moc sprawczą. Jako pedagogiczna forma wypowiedzi ma w twórczości Mysłakowskiego walor szczególny. Pedagogika epistolarna, sprzyjająca ekspresji twórczej, której podstawowym sensem jest doskonalenie aksjologicznej podmiotowości człowieka poprzez wychowanie $\mathrm{w}$ duchu poszanowania

17 E. Rybicka, Antropologiczne i komunikacyjne aspekty dyskursu epistolograficznego, „Teksty Drugie", 4 (2004) s. 40-55.

18 J. Gajda, Pedagogika kultury jako wielki kierunek myśli pedagogicznej, w: tegoż, Pedagogika kultury w zarysie, Kraków 2016, s. 20.

19 Termin „pedagogika epistolarna” i jej konteksty zostanie omówione szerzej w publikacji pt. Transcende te ipsum. O sztuce życia $w$ listach Zygmunta Mysłakowskiego do Joanny Kulmowej (1963-1971), która ukaże się w Wydawnictwie Naukowym Uniwersytetu Szczecińskiego.

20 W rozdziale pt. Zagadnienie kontaktu Mysłakowski napisał: „Co to jest kontakt między ludźmi? $\mathrm{W}$ potocznym znaczeniu jest to każda ustabilizowana forma styczności. Może być to styczność osobista, bezpośrednia, ale może także być i pośrednia, na przykład przez korespondencję"; Z. Mysłakowski, Zagadnienie kontaktu, w: tegoż, O kulturze współżycia, s. 15.

21 L. Marzec, List, „Forum Poetyki”, 2015, lato, s. 86-97. 
wartości moralnych i osobowych, staje się więc w jego twórczości autoteliczną i estetyczną wartością.

\section{List a „moralna gramatyka konfliktów społecznych”}

Jak pisze Danuta Lalak, list jest tekstem wielowarstwowym, który wyróżnia się niekwestionowaną autentycznością na tle innych materiałów autobiograficznych $^{22}$. I takie są listy Mysłakowskiego i Kulmowej, które niemalże od początku ulegają autobiografizacji ${ }^{23}$, a ich autorzy odkrywają siebie coraz bardziej w relacji chiazmatycznej, opartej na obustronnym oddziaływaniu ${ }^{24}$.

Świat społeczny, w jaki wkraczamy, rodząc się i wzrastając to przede wszystkim wspólnota ludzka-prawdziwe, najistotniejsze środowisko istnienia. Ale także jest ono światem konwencji, obyczaju, pojęć, instytucji, wartości, norm, postaw-konwencji, które tworzą olbrzymi system nacisków. Są okresy, kiedy ten system nacisków niszczy wspólnotę, a ona wali się na człowieka całym ciężarem jak dach, nad którym przeszedł huragan ${ }^{25}$

pisał Mysłakowski w 1965 r. do Kulmowej. Jako artysta Mysłakowski posługuje się dodatkowo listem jako tworzywem sztuki. To sztuka stanowi przecież podstawową przestrzeń do rozwoju aktywności artystycznej Kulmowej.

22 D. Lalak, List - funkcje i potencjał biograficzny, w: tejże, A. Ostaszewska, Źródła do badań biograficznych. Listy. Dzienniki. Blogi, Materiały wizualne, Warszawa 2016, s. 19-56.

23 E. Rybicka, Antropologiczne i komunikacyjne aspekty dyskursu epistolograficznego, s. 53.

24 Tamże.

25 List Zygmunta Mysłakowskiego do Joanny Kulmowej wysłany został z Krakowa 17 lutego 1965 r.

26 T. W. Nowacki, Zygmunt Mysłakowski - klucze twórczości 1890-1971 (w setna rocznicę urodzin), „Kwartalnik Pedagogiczny”, 36 (1991) nr 1, s. 46.

27 Tamże, s. 59.

28 List Zygmunta Mysłakowskiego z Krakowa, 16 października 1967.
Jak pisze Tadeusz Nowacki, w autobiograficznej twórczości Mysłakowskiego widoczna jest jego niezwykła wrażliwość na ludzi, krajobraz i przyrodę ${ }^{26}$. Główną część rozważań pedagogicznych Mysłakowskiego także wypełnia człowiek jako istota społeczna ${ }^{27}$.

„Na przyrodę można patrzeć rozmaicie: od strony słonecznej i od strony cienia. Na człowieka można patrzeć tak samo"28 - napisał Mysłakowski w jednym z listów z 1967 r. do Kulmowej. I zaraz dalej dodał: 
W świecie ludzkim odnajdujemy wszystko: poczucie wysokiej godności, ale także zezwierzęcenie, obłudę, łotrostwo, okrucieństwo, do jakiego żadne zwierzę nie jest zdolne. Można więc rozmaicie patrzeć na tę istotę - także tak, jak Różewicz: „ludzkość to takie tworki, w których jedne potworki klepiące paciorki biją drugie potworki klepiące paciorki, w mordki ${ }^{29}$.

Listy Mysłakowskiego, jako autonomiczne teksty kultury, wpisują się idealnie w „teatr życia codziennego" Kulmowej, z wykształcenia aktorki i reżysera. Skuteczność tych listów związanych z prastarą metaforą teatralną ${ }^{30}$ wiąże się ewidentnie z życiem artystycznym Kulmowej i samego Mysłakowskiego. „I tak przechodzimy przez życie grając jakąś rolę, której nie znamy, z tekstem, który tylko co nieco jest nam zrozumiały, w teatrze, o którym właściwie nic nie wiemy: komu służy, w jakim celu..." - pisał Mysłakowski w opowiadaniu Bez tytułu, zamieszczonym w autobiograficznym tomie pt. Zatracone ścieżki, zagubione ślady, który ukazał się w 1967 roku $^{31}$. Dzięki talentowi literackiemu Mysłakowskiego mamy tu do czynienia z artystyczną prozą powieściową najwyższej próby. Opis wydarzeń łączy się z opisem życia wewnętrznego samego Mysłakowskiego. Z jego pamięcią autobiograficzną, w której dzieciństwo i życie rodzinne odgrywają dominującą rolę $e^{32}$. Elementarnymi nauczycielami Mysłakowskiego byli jego rodzice. Ojciec był nauczycielem, matka przejawiała zdolności artystyczne. U Kulmowej matka była nauczycielką języków obcych, a ojciec przejawiał zdolności artystyczne ${ }^{33}$.

„Trzeba umieć czytać Pani poezje, to prawda nie są one dla uczniaków, wyobrażam je sobie recytowane u orfików z towarzyszeniem formingi. Ale dość już się wygadałem: jeszcze Pani powie: znać profesora. Musiał mieć wykład"34 - napisał do Kulmowej. Prof. Mysłakowski składał nieustanne dowody prawdziwej troski o poetkę. Dbał o jej edukację czytelniczą, wysyłał jej cenne książki z własnych zbiorów bibliotecznych, z dedykacjami od Juliana Tuwima, Kazimiery Iłłakowiczówny, polecał najnowsze publikacje z zakresu histo-

29 Tamże.

30 E. Goffman, Człowiek w teatrze życia codziennego, oprac. i wstęp J. Szacki, tłum. H. Datner-Śpiewak, P. Śpiewak, Warszawa 2020.

31 Z. Mysłakowski, Zatracone ścieżki, zagubione ślady, Warszawa 1967, s. 15.

32 Mysłakowscy z Ziemi Dobrzyńskiej, s. 63-72.

33 U. Chęcińska, Pedagogia Joanny Kulmowej w kontekście autobiograficznym, w: Biografie nauczycieli i pedagogów. Idee i programy, red. R. Skrzyniarz, G. Bujak, K. Kołtuniewicz, Lublin 2013, s. 217-228.

34 List z. Mysłakowskiego, 14 kwietnia 1963. 
rii kultury i teorii literatury. A kiedy władze po wypadkach marcowych $1968 \mathrm{r}$. chciały wysiedlić Kulmów ze Strumian, jako pierwszy zaproponował im swoją pomoc. Jako doświadczony pedagog, Mysłakowski próbował wytłumaczyć młodej poetce, że sens życia tkwi także w jego negatywnych stronach, które należy umiejętnie wykorzystać jako szansę na osiągnięcie umiaru i osobistej dojrzałości. Poprzez listy uczy autorkę Fatum na zakręcie historycznej i „moralnej gramatyki konfliktów społecznych"35, trudnej walki o uznanie, z którą łączy się przecież sztuka życia. „Należy bardziej pamiętać o dobru, którego się doznało, niż o krzywdzie. Mściwość góruje tylko u ludzi prymitywnych i egocentrycznych"36 - przestrzegał. Romantyczny idealizm, który charakteryzował intencje i działania Mysłakowskiego, połączył się z bezkompromisowością intelektualną, której pedagog dał szczególny wyraz w listach do poetki, Joanny Kulmowej.

Jako profesor emeritus Mysłakowski odnalazł w Kulmowej idealną partnerkę do epistolarnej komunikacji i fikcjonalizacji obecności ${ }^{37}$.

„Jakże ciężko, mozolnie i z trudem rodzą się owoce na drzewie poznania samego siebie! O ileż więcej i wcześniej zdobywamy wiadomości o rzeczach" - pisał Mysłakowski z zastosowaniem wszystkich „składników autokreacji” ${ }^{\text {”3 }} \mathrm{w}$ jednym z listów do Kulmowej. Jak Wilhelm Dilthey ${ }^{39}$, twórca teorii poznania nauk humanistycznych, uważał, że istotą wychowania jest kształcenie, do którego nie wystarcza tylko znajomość kultury, trzeba tę kulturę przeżyć i zrozumieć.

Mysłakowski w Diltheyowskim stylu łączy przeżywanie z wyrażaniem, odtwórczym myśleniem i rozumieniem. Zgodnie z typologią Edwarda Sprangera, ucznia Diltheya, twórcy filozofii kultury i autora Lebensformen, prof. Mysłakow-

35 A. Honneth, Walka o uznanie. Moralna gramatyka konfliktów społecznych, tłum. J. Duraj, Kraków 2012.

36 Z. Mysłakowski, O sztuce współżycia $w$ granicach podstawowych wartości społecznych, w: tegoż, O kulturze wspótżycia, s. 136.

37 L. Marzec, Interpoetyki korespondencji: figury uobecnienie, fikcjonalizacja i zakłócenia technologii obecności, „Forum Poetyki”, 18 (2019) s. 6-25.

38 List do Euryante pochodzi z Archiwum Rodziny Mysłakowskich.

39 W. Dilthey, Budowa świata historycznego w naukach humanistycznych, tłum. E. Paczkowska-Łagowska, Gdańsk 2004. ski reprezentuje typ estetyczny o ekspresji zmysłowo-obrazowej, który łączy się z typem społecznym o nastawieniu politycznym i umiejętnościach organizacyjnych. Spontaniczność w działaniu, zdolności organizacyjne, zaangażowanie i siła przebicia to cechy charakterologiczne prof. Mysłakowskiego, który pełnił wielokrotnie ważne funkcje: dyrektora, rektora Wyższej Szkoły Pedagogicznej w Krakowie, uczestnika wielu międzynaro- 
dowych konferencji i kongresów ${ }^{40}$. „Im bardziej myślącym jest człowiek, tym niebezpieczniejsza jest jego sytuacja. Im bardziej ucieka się od konwencji epoki, tym bardziej usiłuje się stać sobą"11 - pisał do Joanny Kulmowej w 1963 r.

Korespondencja Kulmowej, która od 1957 r. prowadzi także dziennik ${ }^{42}$, pełni kilka ważnych funkcji jednocześnie: jest rodzajem ekspresyjnej refleksji, wiąże się z „przyjemnością pisania”, ale przede wszystkim jest formą oczyszczenia i autoekspresji ${ }^{43}$. Strumiańskie katharsis obecne w listach Kulmowej do Mysłakowskiego jest rekompensatą za ograniczenia w rzeczywistym świecie ${ }^{44}$.

Prof. Mysłakowski z czasem traktować zaczął poetkę ze Strumian niemalże po ojcowsku. Zwłaszcza po lekturze jej wiersza pt. Navigare necesse est ${ }^{45}$, dedykowanemu ojcu, który zginął w czasie wojny, gdy Kulmowa miała piętnaście lat. Przez całe życie poetka zmagała się z nierozwiązanym problemem z okresu adolescencji. Mysłakowski jako pedagog doskonale zrozumiał traumę Kulmowej wyniesioną z wojennego dzieciństwa. Skonstruował więc epistolarno-kompensacyjny wizerunek ojca, którym sam stał się w pewnym sensie dla Kulmowej. Złożoność relacji między ojcem a dzieckiem pojawiała się wielokrotnie w listach Mysłakowskiego, który analizował także swoje własne relacje z synami ${ }^{46}$. Zwłaszcza z najstarszym synem, Andrzejem, który zmarł niespodziewanie w 1963 r. Ojcostwo przeżywane w wymiarze straty stało się tematem wielu listów do Kulmowej. „Tragiczne «duże miłoście» ojca do dziecka i na odwrót, dziecka do ojca, które rzadko kiedy się zrastają, najczęściej rozmijają się w czasie. Pozostaje żal i tęsknota, niczym nie zaspokojona. Dużo można by na ten temat mówić. Są tam także jakieś ciemne przepaście"47 - napisał do Kulmowej 11 kwietnia 1963 r. Jak pisał Stanisław Kawula $^{48}$, to Mysłakowski zainicjował

40 Zygmunt Karol Mysłakowski, w: Leksykon Profesorów Akademii Pedagogicznej im. Komisji Edukacji Narodowej 1946-2006, red. J. Hampel, F. Kiryk, I. Pietrzkiewicz, Kraków 2006, s. 377-378.

41 List Zygmunta Mysłakowskiego wysłany z Krakowa, 21 marca 1963.

42 Kulmowa nazwała swój dziennik Pamiętnikiem, choć ma on wszelkie cechy dziennika; P. Rodak, Między zapisem a literatura. Dziennik polskiego pisarza w XX wieku, Warszawa 2011.

43 Z. Mysłakowski, Bez tytułu, w: Zatracone ścieżki, zagubione ślady, Warszawa 1967, s. 15.

44 A. Pekaniec, Listy kobiet. Historia, interpretacja, recepcja. Rekonesans, w: tejże, Autobiografki. Szkice o literaturze dokumentu osobistego kobiet, Kraków 2020, s. 66-95.

45 J. Kulmowa, Navigare necesse est, w: tejże, Boże umieranie, Warszawa 1962, s. 94.

46 Temat ten podejmie w rozdziale pt. $W$ pustyni czy w społeczności; w: Z. Mysłakowski, O kulturze wspótżycia, s. 16-113.

47 List, 11 kwietnia 1963.

48 S. Kawula, Rodzina w badaniach pedagogicznych Zygmunta Mysłakowskiego, w: W poszukiwaniu podstaw pedagogiki, s. 129-143. 
pierwsze w Polsce badania nad życiem rodzinnym i rodzinnym środowiskiem wychowawczym. Swoim zainteresowaniom tematyką rodzinną dał wyraz w dwóch ważnych publikacjach: Rodzina wiejska jako środowisko wychowawcze i Wychowanie w środowisku małomiasteczkowym. Był prekursorem badań w zakresie metodologii badań pedagogicznych nad typami rodzin polskich.

\section{List wobec sztuki życia}

Ja mam swoje kłopoty, ale jeszcze jakoś się trzymam, o tyle przynajmniej, że mogę dalej pracować naukowo, a po trosze także literacko. Dużo czytam w wolnych chwilach, uzupełniając swoją zaniedbaną dawniej klasykę. Czytam Cycerona, Senekę, Epikura i to mi daje dużo zadowolenia. Piszę jednocześnie dwie książki, jedną raczej naukową, drugą literacką. Mam jednak poważne obawy czy je wydadzą. Czy znajdą tyle tolerancji i odwagi? ${ }^{49}$

- pisał w 1965 r. Literatura i sztuka zawsze były dla niego źródłem przyjemności estetycznej. Wychowanie hellenistyczne, którego wielkimi zwolennikami byli Mysłakowski i Kulmowa, nie mogło więc obyć się bez dziedziny artystycznej. „Trzeba zanurzyć się w poezję, jak w muzykę, jak w żywioł i nie próbować jej zrozumieć, jak się na przykład rozumie zadanie arytmetyczne" - pisał autor Listów do Euryante ${ }^{50}$.

Mysłakowski w listach do Kulmowej wskazywał, że to poezja przyczyniła się do wprowadzenia człowieka na wyższy stopień życia duchowego. To dzięki

49 List Z. Mysłakowskiego wysłany z Krakowa, 17 grudnia 1965 .

50 Listy do Euryante pozostały w archiwum rodziny Mysłakowskich. Jeden z listów pt. W obronie poetów Mysłakowski wysłał do Strumian w 1963 r.

51 „Poczucie człowieczeństwa i jego godności jest odwieczną zdobyczą pokoleń. Ta «megalopsychija» - jak to starożytni Grecy nazywali - ten wyraz najwyższego poczucia odpowiedzialności i integralności bytu ludzkiego - jest triumfem kolektywnego doświadczenia" - pisał Mysłakowski w rozdziale pt. Doświadczenia potoczne, naukowe, i światopoglądowe; Z. Mysłakowski, O kulturze współżycia, s. 94. List Z. Mysłakowskiego, 10 października 1964. poezji, jak twierdził, człowiek zdobywa własne doświadczenie psychologiczne, wyczucie wartości moralnych, a dzięki katharsis doznaje głębokiej przemiany i uczy się sztuki życia. Szeroko pojęty humanizm stał się podstawą wychowania Mysłakowskiego, który Morze Śródziemne i wyspy greckie uważał za swoją drugą ojczyznę.

Kulmowa, zainspirowana listami prof. Mysłakowskiego, odwoływała się często w swojej twórczości do greckiej megalopsychii ${ }^{51}$, kaloka- 
gatii i sztuki życia. W listach do prof. Mysłakowskiego pokazywała siebie jako wielowymiarową postać. Pisała z otwartością, odwagą, wieloznacznością i wyrazistością point, które wydawać się będą jak na tamte czasy zaskakujące, bo wywiedzione $\mathrm{z}$ bogactwa jej oryginalnych myśli, niekonwencjonalnych wrażeń i spostrzeżeń.

Potrzeba odosobnienia i samotności, bliska romantycznemu modelowi samotnego twórcy, realizowała się w Strumianach. Wbrew romantycznym deklaracjom Kulmowa pragnęła jednak wsparcia emocjonalnego i zrozumienia.

Kiedy więc w jednym z pierwszych listów do prof. Mysłakowskiego napisała o „maleńkiej zmowie milczenia krytyków”, którzy nie dostrzegają jej twórczości i nie wpisują jej wystąpień poetyckich w pokoleniową wspólnotę tzw. pokolenia 56, Mysłakowski podał jej za przykład Cypriana Kamila Norwida, ale także Stanisława Wyspiańskiego, Augusta Rodina i Wincentego Van Gogha. Jako antytezę przedstawił Jarosława Iwaszkiewicza, wieloletniego prezesa Związku Literatów Polskich, dyplomatę, posła na Sejm, o którego twórczości pisał wielokrotnie Ryszard Matuszewski. „Poezja jest bliższą prawdą o człowieku niż arkusze personalne nawet najrzetelniej spisane" ${ }^{\prime 52}$ - napisał autorytatywnie Mysłakowski w Listach do Euryante. Pedagog sam uprawiał sztukę, przyjaźnił się przez wiele lat głównie z malarzami i rzeźbiarzami, profesorami krakowskiej Akademii Sztuk Pięknych: Zbigniewem Pronaszką, Zdzisławem Gedliczką i Xawerym Dunikowskim. Łączył własne zainteresowania literackie z twórczością Juliana Tuwima, Jerzego Lieberta, Stanisława Wyspiańskiego, Bolesława Leśmiana. Kontakty z krakowskimi pisarzami: Julianem Przybosiem, Adamem Polewką i artystami: Tadeuszem Kantorem, Władysławem i Józefem Jaremami traktował jako ważne znajomości towarzyskie. Pisał o tym w listach do Kulmowej. Listy Mysłakowskiego do Poetki ze Strumian mają więc szczególny wymiar osobisty.

\section{List $i$ antropozofia pedagogiczna}

Zygmunt Mysłakowski konsekwentnie wypracował własny oryginalny styl, widoczny szczególnie w korespondencji do Kulmowej. Ascetyzm formy, rygoryzm kompozycyjny, przenikliwość myśli, delikatna ironia, prosty język bliskie są Norwidowi. Autor Zatraconych ścieżek, zagubionych śladów interesował się szczególnie twórczością Norwida, ale także Wyspiańskiego, czytał i analizował powieści 52 List do Euryante pt. W obronie poetów. 
Witolda Gombrowicza i wiersze Konstantego Ildefonsa Gałczyńskiego. Tak jak Leonardo da Vinci, którego twórczością się pasjonował ${ }^{53}$, studiował najpierw nauki przyrodnicze, a potem filozofię. Początkowo na Uniwersytecie Jagiellońskim, a potem na Sorbonie. Od 1937 r. Mysłakowski należał do Towarzystwa Fotograficznego, a potem do Polskiego Związku Fotografików Polskich. Jego portrety prof. Adama Krzyżanowskiego i prof. Konstantego Laszczki były wyróżniane i nagradzane na wystawach m.in. w Chicago i Ottawie.

Od 1945 r. Mysłakowski należał do Związku Zawodowego Artystów Plastyków w Krakowie. Wraz z Emilem Zegadłowiczem, Leonem Kruczkowskim, Feliksem Grossem, Ignacym Fikiem założył w Krakowie pierwszą Spółdzielnię Wydawniczą „Czytelnik”. Od 1945 r. należał do Związków Literatów Polskich. Przed wojną współpracował z czasopismami literackimi „Sfinks” i „Zdrój”. Publikował swoje artykuły w lwowskiej „Gazecie Literackiej”, „Nowinach Literackich”, a po wojnie w „Kuźnicy”. Bardzo dobra znajomość języków obcych, w tym łaciny i greki, ułatwiała mu pracę naukową i kontakty zagraniczne. Mysłakowski, który jako więzień obozu w Sachsnehausen „poznał smak egzystencji odartej z wszelkiej godności" ${ }^{\prime \prime}$, a po wojnie doświadczył wielokrotnie braku uznania i zrozumienia, napisał w listach do Kulmowej, że zalety intelektualne rzadko kiedy przynoszą człowiekowi satysfakcjonujące kontakty międzyludzkie. Zalety intelektualne, jako byty idealne, są jedynie niewyczerpanym źródłem satysfakcji wewnętrznej, przynoszą ukojenie i entuzjazm własny. Przyjemnie jest go doświadczać, mając w świadomości poczucie własnej oryginalności i niepospolitości, ale trudno jest z tego powodu zasłużyć sobie na ludzkie uznanie i podziw. Mysłakowski, który sam doświadczał wielokrotnie braku uznania i społecznej akceptacji, za wzór sta-

53 W archiwum rodziny Mysłakowskich pozostał niewydany tom poświęcony życiu i twórczości Leonarda da Vinci. Monografia pt. Lionardo da Vinci. Apokryfy i rzeczywistość (1950-1955) pozostała w rękopisie; P. Mysłakowski, Ojciec - inne oblicze uczonego, w: $W$ poszukiwaniu podstaw pedagogiki, s. 243-244.

54 Frankl V. E., Człowiek $w$ poszukiwaniu sensu. Głos $z$ otchłani Holocaustu, tłum. A. Wolnicka, Warszawa 2020, s. 11.

55 O. Chajjam, Rubajaty, tłum. z perskiego A. Gawroński, wstęp i komentarz F. Machalski, Wrocław 1971. wiał poetce, przepełnione afirmacją życia, Rubajaty Omara Chajjama ${ }^{55}$, w których widział głębię filozoficznej myśli, a przede wszystkim niepowtarzalność i prostotę formy. W poezji Kulmowej dostrzegł „dynamikę Rimbauda i ironię Norwida” oraz „zwartość myśli godną Pascala". Zwracał uwagę na muzyczność poezji Kulmowej, „rymy odciążone od banalności i mechanicznych powtórzeń, nowe 
poetyckie odkrywcze zestawienia słów przełamujące martwotę konwencjonalnej mowy i pragmatyzm myślenia". Mysłakowski fascynował się niezwykłą kondensacją wyobraźni i emocji, z którą Kulmowa łączyła precyzję własnej wypowiedzi. Połączyły się one w sposób kongenialny ze wzniosłością stylu, z jego malowniczością, wybornością, ale i z ironią. A wszystko po to, by „odpowiednie dać rzeczy słowo". Mysłakowski, podobnie jak Norwid, którego nieznane utwory odkrył w 1916 r. i którego cenił i podziwiał, miał zwielokrotnioną wrażliwość artystyczną wynikającą z uprawianych przez niego sztuk ${ }^{56}$. Cały swój wysiłek twórczy podporządkował poszukiwaniom prawdy o człowieku.

Człowiek dla mnie istnieje tylko dzięki uczuciu dla innego człowieka, dzięki temu zapatrzeniu, które sprawia że sam potrafı się nawet unicestwić. Kiedy roztapia się w drugiej istocie-zaczyna istnieć. [...] Skromną cząstkę tych prawd (moich prawd subiektywnych) zamierzam zamieścić w pisanej dla dzieci „Leokadii” i może dlatego tak bardzo jestem przywiązana do tej książki ${ }^{77}$

napisała Kulmowa do Mysłakowskiego. „Co wiemy naprawdę o człowieku? I skąd ma przyjść do nas ta wiedza? Gdzie mamy czerpać tę niesfałszowaną, nie zmitologizowaną, nie ulepioną dla propagandy, prawdę o człowieku?" - zadał pytanie w jednym z Listów do Euryante Mysłakowski. Pisane do szuflady Listy do Euryante ${ }^{58}$ stanowią najdoskonalszą egzemplifikację pedagogiki epistolarnej Mysłakowskiego, którą jako pedagog uprawiał konsekwentnie przez całe życie.

„Bliskość pokrewnego człowieka” stała się w ostatnich latach życia wielką potrzebą prof. Mysłakowskiego. O jego pedagogicznej twórczości Tadeusz Nowacki napisał, że w całości skoncentrowana była na człowieku. A ze względu na jej liczne odwołania do filozofii, literatury, kultury i sztuki można by ją potraktować jako antropozofię pedagogiczną ${ }^{59}$, wymagającą aktywnego „obcowania za pośrednictwem książki"6o i aktywnego

56 Z. Mysłakowski, Nieznane utwory Cypriana Norwida, „Sfinks”, 9 (1916) z. 4, s. 11-18; tegoż, Nieznane utwory Cypriana Norwida, „Zdrój” (Poznań), 1918, z. 4, s. 97-102.

57 List Joanny Kulmowej, 14 kwietnia 1965.

58 Tajemnicze Listy do Euryante pozostały nadal w archiwum Zygmunta Mysłakowskiego. W przygotowywanej do druku monografii pt. Transcende te ipsum być może odnajdą swoje właściwe miejsce.

59 T. W. Nowacki, Zygmunt Mysłakowski - klucze twórczości, s. 64.

6o Z. Mysłakowski, Obcowanie za pośrednictwem książki, w: tegoż, O kulturze współżycia, s. 79. 
uczestnictwa w życiu społecznym. „Człowiek jest istotą nieznaną. Jest także istotą otwartą, niedokończoną, mającą przed sobą ogromne możliwości rozwoju"61 pisał Mysłakowski w 1967 r. w tomie pt. O kulturze wspótżycia. Myśl Mysłakowskiego przypomina obecnie myśl Chantal Delsol w eseistycznych rozważaniach wyrażonych w tomie pt. Czym jest człowiek? Kurs antropologii dla niewtajemniczonych. W $2008 \mathrm{r}$. francuska filozofka napisała bowiem, że „człowiek rodzi się osobliwie niedokończony i do osiągnięcia statusu człowieka natura mu nie wystarcza" ${ }^{\prime 2}$. Potwierdzając tym samym myśl Mysłakowskiego, że zakorzenienie w kulturze jest koniecznością, tak jak przekaz kulturowy jest moralnym i koniecznym zachowaniem człowieka. Bez kulturowego przekazu kultura nie może przetrwać i połączyć się ze sztuką życia, z którą zawsze łączyć się będzie przecież sztuka słowa. Listy prof. Mysłakowskiego do Kulmowej egzemplifikują związki kultury edukacji ${ }^{63}$ z kulturą słowa, która łączy się zawsze ze sztuką życia. Wynika ona z sytuacji epistolarnej nadawcy i odbiorcy, z umiejętności współtworzenia przez nich kulturalnych więzi międzyludzkich. Powstają one wtedy, kiedy komunikują się ze sobą osoby wybitne, o ogromnym potencjale twórczym, posiadające wysoką kulturę korespondowania.

\section{Zakończenie}

„Biografia jest fenomenem edukacyjnym"64 - pisze Elżbieta Dubas. Takim samym fenomenem edukacyjnym staje się list. W oryginalnej koncepcji Skwarczyńskiej piękno listu powinno wynikać z postawy życiowej adresata jako współtwórcy listu, z jego potrzeby kontaktu z drugim człowiekiem. Najlepszym dowodem na to są listy prof. Zygmunta Mysłakowskiego pisane do Joanny Kulmowej. Autor Wychowania człowieka w zmiennej rzeczywisto-

61 Tamże, s. 48

62 Ch. Delsol, Przekaz, w: tejże, Czym jest człowiek? Kurs antropologii dla niewtajemniczonych, tłum. M. Kowalska, Kraków 2011, s. 123.

63 J. Bruner, Kultura edukacji, tłum. T. Brzostowska-Tereszkiewicz, Warszawa 2010.

64 E. Dubas, Wstęp, w: $W$ stulecie metody biograficznej. Refleksje i przykłady badań z perspektywy polsko-frankofońskiej, Łódź 2020, s. 8. ści już jako professor emeritus dokonuje w nich podsumowania i refleksji. Ocenia własny „plan życiowy”. Sam to pojęcie wprowadził w obieg naukowy, sam w niekonwencjonalny sposób ocenia jego realizację w emocjonalnych listach do Kulmowej. Były one dla poetki ważną lekturą i estetycznym przeżyciem. Jak zauważył Stefan 
Baścik ${ }^{65}$, Mysłakowski zawsze dbał o walory estetyczne swoich wypowiedzi, wzorem Norwida cyzelował swoje teksty, dbał o ich komunikatywność i poprawność, szukał słów jedynych i niepowtarzalnych. Piękno listu, tak jak piękno rozmowy, wynika bowiem z autentycznej potrzeby kontaktu z drugim człowiekiem. I tak się właśnie dzieje w listach prof. Mysłakowskiego do poetki Kulmowej. Między światem nauki i sztuki a światem ludzkich zmysłów, doskonalonych przez Mysłakowskiego poprzez uprawianie pedagogiki epistolarnej, widoczny jest ścisły związek.

„Drogi Panie Profesorze, sportretować Pana mogę tylko listem. Bo cała nasza przyjaźń to były właściwie tylko listy, poza tym odwiedziłam Państwa jeden raz, kiedy byłam w Krakowie, żeby chłonąć podwawelską jesień" ${ }^{66}$ - pisała Joanna Kulmowa w 1995 r. w autobiograficznym tomie pt. Ciułanie siebie, w którym umieściła epistolarny portret prof. Mysłakowskiego. Epistolarność zawsze spełniała ważną funkcję intelektualną ${ }^{67} \mathrm{w}$ życiu i w pracy naukowej prof. Mysłakowskiego, a u schyłku życia stała się jednym z głównych narzędzi myślenia i przeżywania świata. Jak sztuka rozmowy, która zawsze była dla Mysłakowskiego ważną intelektualną potrzebą i zobowiązaniem edukacyjnym ${ }^{68}$. Renesansowe bogactwo myśli prof. Mysłakowskiego, obecne w jego twórczości naukowej już od czasów studiów na Uniwersytecie Jagiellońskim, odnalazło swój szczególny wyraz w listach do Kulmowej, która po latach napisała z wdzięcznością: „I tak - mimowolnie albo nawet wbrew swojej woli - zasiał mi Pan ziarenko mojej przemiany. Kierunek poezji też Panu zawdzięczam. Gdyby nie Pan, poszłabym pewnie $w$ inną stronę, mniej własną. A przecież to były tylko listy, Panie Profesorze..."69.

Korespondencja Joanny Kulmowej z prof. Zygmuntem Mysłakowskim, po wydanych wcześniej listach Joanny Kulmowej wymienianych z prof. Heinrichem Kunstmannem $^{70}$ i Wisławą Szymborską ${ }^{71}$, stanowić będzie trzeci najważniejszy

65 S. Baścik, Życiorys naukowy Prof. Dra Zygmunta Mysłakowskiego, w: Z. Mysłakowski, Pisma wybrane, red. T. Nowacki, Warszawa 1971, s. 15-16.

66 J. Kulmowa, Portret Dwudziesty Drugi. Sól i kamień, w: tejże, Ciułanie siebie, Warszawa 1995, s. 224.

67 P. Rodak, Jean Hebrard: między oralnościa a piśmiennością, w: tegoż, Pismo, książka, lektura. Rozmowy: Le Goff, Chartier, Hebrard, Fabre, Lejeune, Warszawa 2009, s. 179.

68 Z. Mysłakowski, Sztuka rozmowy, w: tegoż, O kulturze wspótżycia, s. 6-61.

69 Tamże, s. 226.

$70 \mathrm{Na}$ początku Kunstmann wymyślił sobie Kulmowa. Heinrich Kunstmann - Joanna Kulmowa. Listy 1966-2009, tłum. M. Zybura, oprac. U. Chęcińska i M. Zybura, Szczecin 2016.

71 Tak wygląda prawdziwa poetka. Podciągnij się, wstęp , oprac. i posłowie U. Chęcińska, Kraków 2019. 
tom listów ze Strumian. Dopełniony on zostanie wyborem myśli o sztuce życia wyrażonych przez prof. Zygmunta Mysłakowskiego w szczególny sposób w niezwykłych listach do Joanny Kulmowej.

Listy Zygmunta Mysłakowskiego do Joanny Kulmowej to rodzaj pedagogiki epistolarnej stanowiącej zbiór praktycznych porad o sztuce życia i towarzyszącym jej semantycznym wymiarom człowieczeństwa. Należy je potraktować jako ostatnie, niezwykłe dzieło życia autora Zatraconych ścieżek, zagubionych śladów, który zmarł 1 października 1971 roku, równo pięćdziesiąt lat temu...

Streszczenie: W 2021 r. przypada 50. rocznica śmierci prof. Zygmunta Mysłakowskiego (1890-1971), wybitnego pedagoga kultury, teoretyka edukacji, filozofa i artysty. „Jestem przekonany, że istnieje pokrewieństwo między twórczością naukową i artystyczną, która dochodzi do głosu w syntezie naukowej zjawisk" - napisał Z. Mysłakowski. Tę myśl potwierdza korespondencja prof. Z. Mysłakowskiego z poetką i pisarką Joanną Kulmową (1928-2018). Jest to szczególny rodzaj pedagogiki kultury. Można by ją nazwać pedagogiką epistolarną, definiowaną jako rodzaj psychologicznej i pedagogicznej refleksji nad światem kultury. Pedagogika epistolarna, sprzyjająca twórczej ekspresji, staje się w twórczości Z. Mysłakowskiego autoteliczną i estetyczną jakością. Jest to związane ze stałym systemem kulturalnych odniesień i kontekstów kulturowych wpisanych we współczesny autobiograficzny dyskurs naukowy poprzez list jako dokument osobisty. Artykuł jest zapowiedzią publikacji listów prof. Z. Mysłakowskiego do J. Kulmowej.

Słowa kluczowe: pedagogika epistolarna, pedagogika kultury, biografia, list, Zygmunt Mysłakowski, Joanna Kulmowa.

\section{Bibliografia}

Banach Cz., Wspomnienie i rozmowa o profesorze Zygmuncie Mysłakowskim, w: W poszukiwaniu podstaw pedagogiki. Zygmunt Mysłakowski (1890-1971), red. T. Nowacki, Warszawa 1999, s. 267-279.

Baścik S., Życiorys naukowy Prof. Dr. Zygmunta Mysłakowskiego, w: Z. Mysłakowski, Pisma wybrane, red. T. Nowacki, Warszawa 1971, s. 9-35.

Bibliografia i ikonobibliografia twórczości Joanny Kulmowej, oprac. i wstęp U. Chęcińska, Szczecin 2012.

Bruner J., Kultura edukacji, tłum. T. Brzostowska-Tereszkiewicz, Warszawa 2010.

Całek A., Nowa teoria listu, Kraków 2019.

Cysewski K., Problem autokreacji w listach Zygmunta Krasińskiego, w: Sztuka pisania. O liście polskim w wieku XIX, red, J. Sztachelska, E. Dąbrowicz, Białystok 2000, s. 73-97. 
Chmaj L., Prądy i kierunki w pedagogice XX wieku, Warszawa 1963.

Chajjam O., Rubajaty, przeł, z perskiego A. Gawroński, wstęp i komentarz F. Machalski, Wrocław 1971.

Chęcińska U., Edukacja małego dziecka. Joanny Kulmowej pajdologia poetycka in extenso, w: Children in the Postmodern World. Culture - Media - Social Inequality, red. H. Krauze-Sikorska, M. Klichowski, A. Basińska, Poznań 2014, s. 269-281.

Chęcińska U., Pedagogia Joanny Kulmowej w kontekście autobiograficznym, w: Biografie nauczycieli i pedagogów. Idee i programy, red. R. Skrzyniarz, G. Bujak, K. Kołtuniewicz, Lublin 2013, s. 217-228.

Chęcińska U., Poetka i paidia. O muzie dziecięcej Joanny Kulmowej, Szczecin 2006.

Delsol Ch., Czym jest człowiek? Kurs antropologii dla niewtajemniczonych, tłum. M. Kowalska, Kraków 2011.

Dilthey W., Budowa świata historycznego w naukach humanistycznych, tłum. E. Paczkowska-Łagowska, Gdańsk 2004.

Dubas E., W stulecie metody biograficznej. Refleksje i przykłady badań z perspektywy polsko-frankofonskiej, Łódź 2020.

Frankl V. E., Człowiek w poszukiwaniu sensu. Głos z otchłani Holocaustu, tłum. A. Wolnicka, Warszawa 2020.

Gajda J., Pedagogika kultury w zarysie, Kraków 2016.

Goffman E., Człowiek $w$ teatrze życia codziennego, oprac. i wstęp J. Szacki, tłum. H. Datner-Śpiewak, P. Śpiewak, Warszawa 2020.

Honneth A., Walka o uznanie. Moralna gramatyka konfliktów społecznych, tłum. J. Duraj, Kraków 2012.

Joanna Kulmowa. Doctor Honoris Causa Uniwersytetu Szczecińskiego, red. U. Chęcińska, Szczecin 2012.

Joanna Kulmowa wobec świata literatury, red. U. Chęcińska, Szczecin 1998.

Kawula S., Rodzina $w$ badaniach pedagogicznych Zygmunta Mysłakowskiego, w: W poszukiwaniu podstaw pedagogiki. Zygmunt Mysłakowski (1890-1971), red. T. Nowacki, Warszawa 1999, s. 129-143.

Książek-Szczepanikowa A., Zawiązki Joanny Kulmowej wielokrotnie odczytane. Tekst rozumienie - aplikacja, Szczecin 2001.

Książek-Szczepanikowa A., „Na ten słodki czas”. Spotkania z Joanną Kulmową i jej poezją w latach 1982-1996, Siedlce 2004.

Książek-Szczepanikowa A., Joanny Kulmowej „poezja otwarta”, Łódź 2017.

Kulmowa J., Boże umieranie, Warszawa 1962.

Kulmowa J., Ciułanie siebie, Warszawa 1995.

Lalak D., Ostaszewska A., Źródła do badań biograficznych. Listy. Dzienniki. Blogi, materiały wizualne, Warszawa 2016

Marzec L., List, „Forum Poetyki”, 2015, lato, s. 86-97.

Marzec L., Interpoetyki korespondencji: figury uobecnienie, fikcjonalizacja i zakłócenia technologii obecności, „Forum Poetyki”, 18 (2019) s. 6-25. 
Michalski G., Zygmunt Mysłakowski (1890-1971). Działalność i twórczość pedagogiczna, Łódź 1994.

Mysłakowski P., Mysłakowscy z Ziemi Dobrzyńskiej. W górę rzeki. Wspomnienia, teksty i materiaty, Warszawa 1997.

Mysłakowski Z., Nieznane utwory Cypriana Norwida, „Sfinks”, 9 (1916), z. 4, s. 11-18.

Mysłakowski Z., Nieznane utwory Cypriana Norwida, „Zdrój” (Poznań), 1918, z. 4, s. 97-102.

Mysłakowski Z., O kulturze wspótżycia. Rozważania i propozycje, Warszawa 1967.

Mysłakowski Z., Pisma wybrane, red. T. Nowacki, Warszawa 1971.

Mysłakowski Z., Zatracone ścieżki, zagubione ślady, Warszawa 1967.

Na początku Kunstmann wymyślił sobie Kulmowa. Heinrich Kunstmann - Joanna Kulmowa. Listy 1966-2009, tłum. M. Zybura, oprac. U. Chęcińska i M. Zybura, Szczecin 2016.

Nowacki T. W., Recepcja myśli pedagogicznej Zygmunta Mysłakowskiego, w: W poszukiwaniu podstaw pedagogiki. Zygmunt Mysłakowski (1890-1971), red. T. Nowacki, Warszawa 1999, s. 196-213.

Nowacki T. W., Zygmunt Mysłakowski - klucze twórczości 1890-1971: (w setna rocznice urodzin), „Kwartalnik Pedagogiczny”, 26 (1991) nr 1, s. 49-71

Okoń W., Zygmunt Mysłakowski-pedagog dwóch epok, w: W. Okoń, Wizerunki sławnych pedagogów polskich, Warszawa 2000, s. 309-333.

Pekaniec A., Autobiografki. Szkice o literaturze dokumentu osobistego kobiet, Kraków 2020.

Rodak P., Pismo, książka, lektura. Rozmowy: Le Goff, Chartier, Hebrard, Fabre, Lejeune, Warszawa 2009.

Poetka i paidia. O muzie dziecięcej Joanny Kulmowej, Szczecin 2006.

Rodak P., Między zapisem a literaturą. Dziennik polskiego pisarza w XX wieku, Warszawa 2011.

Rybicka E., Antropologiczne i komunikacyjne aspekty dyskursu epistolograficznego, „Teksty Drugie", 4 (2004) s. 40-55.

Szmyd K., Zygmunt Karol Mysłakowski (1890-1971). Twórczość i wkład do rozwoju nauk o wychowaniu, Rzeszów 1997.

Skwarczyńska S., Teoria listu, na podstawie lwowskiego pierwodruku opracowali E. Feliksiak, M. Leś, Białystok 2006.

Tak wygląda prawdziwa poetka. Podciagnij się, wstęp, oprac. i posłowie U. Chęcińska, Kraków 2019.

Torowska J., Selected Aspects of Zygmunt Mysłakowski's Work Entitled O kulturze wspótżycia. Rozważania i propozycje [On the Culture of Coexistence: Considerations and Propositions] in the Light of His Biography, „Biografistyka Pedagogiczna”, 5 (2020) nr 2, s. 125-149, DOI: 10.36578/BP.2020.05.07.

Zygmunt Karol Mysłakowski, w: Leksykon Profesorów Akademii Pedagogicznej im. Komisji Edukacji Narodowej 1946-2006, red. J. Hampel, F. Kiryk, I. Pietrzkiewicz, Kraków 2006, s. 377-378. 